九州大学学術情報リポジトリ

Kyushu University Institutional Repository

Overview of the joint industrial project for practical application of laser-arc hybrid welding in construction of general merchant ships in Japan

Gotoh, Koj i

Kyushu University

Uemura, Takamori

Kyushu University

Uchino, Issei

Namura Shipbuilding Co. Ltd.

Narimatsu, Hisao

Tsuneishi Shipbuilding Co., Ltd.

他

ht tp://hdl. handle. net/2324/4752585

出版情報: Proceedings of the 14th International Symposium, PRADS 2019, September 22-26, 2019, Yokohama, Japan- Volume III. 65, pp.258-272, 2020-10-04. Springer

バージョン :

権利関係 : 


\title{
Overview of the joint industrial project for practical application of laser-arc hybrid welding in construction of general merchant ships in Japan
}

\author{
Koji Gotoh $^{1}$, Takamori Uemura ${ }^{1}$, Issei Uchino ${ }^{2}$, Hisao Narimatsu ${ }^{3}$, Toshimitsu \\ Maeda $^{4}$ and Takumi Torigoe ${ }^{4}$, Atsuo Moriyama ${ }^{5}$ \\ ${ }^{1}$ Kyushu University, Motooka 744 Nishi-ku Fukuoka 819-0395, Japan \\ ${ }^{2}$ Namura Shipbuilding Co. Ltd., Shioya 5-1 Kurokawa Imari 848-0121, Japan \\ ${ }^{3}$ Tsuneishi Shipbuilding Co., Ltd., Tsuneishi 1083 Numakumao Fukuyama 720-0393, Japan \\ ${ }^{4}$ Maeda Kogyo Co., Ltd., 22 Yon-No-Shimo Nawa Tokai 476-0002, Japan \\ 5 Japan Ship Technology Research Association, Akasaka 2-10-9 Tokyo 107-0052, Japan \\ gotoh@nams.kyushu-u.ac.jp
}

\begin{abstract}
The application of advanced welding technologies is important for improving the efficiency of hull construction processes and reducing production costs. Laser-arc hybrid welding technology, which combines the advantages of laser and normal arc welding, is of high quality and is expected to improve productivity. The Japan Ship Technology Research Association has organized the joint industry project in collaboration with a university, a classification society and some shipyards to apply this technology in the construction of general merchant ships, in which the plate thickness of the main structural member is thicker than passenger ships and high speed craft. The overview of the first phase JIP results were introduced in PRADS 2016. In this presentation, an overview of main research results of the second and third phase JIP, which are listed below, are introduced.
\end{abstract}

Keywords: laser-arc hybrid welding, hull construction, full-penetration tee joint by one-side single-pass welding, weld groove processing, weld seam tracking

\section{Introduction}

Advanced welding technologies can contribute to improving the efficiency of hull construction and to reducing production costs. In addition, the accuracy of hull construction is directly related to the structural integrity of the hull structures.

Laser-arc hybrid welding technology, which has the advantages of laser and conventional arc welding, provides high-quality welds and is expected to improve productivity and accuracy [1][2]. Sufficient reductions in residual welding deformation in hull structures are expected by applying laser-arc hybrid welding because a major advantage of laser-arc hybrid welding is its low heat input compared with conventional arc welding. 
Such improvements will increase the productivity of hull construction and permit structural styles that reduce the net weight of the hull. However, the following difficulties arise when applying hybrid welding to hull construction.

1. The plate of a stiffener is expected to have thickness of at least $10-15 \mathrm{~mm}$. Such plates are often used for general cargo ships. To date, the applicable plate thicknesses of laser-arc hybrid welds are no more than about $10 \mathrm{~mm}$.

2. Although grooves are usually mechanically cut to avoid the occurrence of weld defects, it is necessary to thermally cut grooves during hull construction.

3. A pure- $-\mathrm{CO}_{2}$ shield gas needs to be applied in the place of a $\mathrm{CO}_{2}$ and argon mixed gas to reduce the construction cost.

4. Laser power sources are expensive compared with other construction tools.

5. It is necessary to check the effect of primer paint, which prevents corrosion of welded joints, on the structural integrity of the welded joint.

A joint industrial research project focusing on the applicability of laser-arc hybrid welding in the construction of general merchant ships was organized by the Japan Ship Technology Research Association and supported by the Nippon Foundation and the Shipbuilding Research Centre of Japan. The research was conducted from 2012 to 2014. The achievement of this JIP was presented in PRADS 2016 [3] and the guidelines of laser-arc hybrid welding for hull construction was published by Class NK [4] according to the JIP results. However, several research subjects that could not be addressed in this research project were pointed out. Therefore, new members joined the JIP and a new JIP worked to solve these problems. In this presentation, an overview of the main research results of the second phase JIP are introduced.

\section{Full-penetration tee joint by one-side single-pass welding}

\subsection{Investigation of appropriate welding conditions}

Achievement of our first phase JIP indicates the possibility of the fabrication of the fullpenetration tee joint with stiffener thickness is about $15 \mathrm{~mm}$ by one-side single-pass welding is expected by applying the laser-arc hybrid welding. We conducted experiments to establish the welding procedure for fabrication of this type joint. The applied material, welding consumable and shielded gas are shown in Table 1. Specifications of power sources applied in this JIP are shown in Table 2. These materials were applied by considering the situation currently used in hull construction in Japan. The same materials were also applied in the investigations introduced the following sections.

The specimen configuration is shown in Fig. 1. Residual oxide film generated by laser cutting and anti-rust primer was removed to prevent the generation of blowhole and other weld defects.

To investigate suitable welding conditions, various welding parameters as control factors and noise factors were set, as shown in Table 3 , and assigned control factors to Taguchi experimental design-L18 orthogonal array tables. Other welding conditions were set as constant values shown in Table 4 . 
Table 1. Materials of the plate and weld wire used.

\begin{tabular}{ll}
\hline Material: & $\begin{array}{l}\text { High-tensile steel, grade KD36 approved by Nippon } \\
\text { Kaiji Kyokai (Class NK) }\end{array}$ \\
\hline Plate thickness: & $\begin{array}{l}\text { Thickness 14 mm for stiffener and } 21 \mathrm{~mm} \text { for base } \\
\text { plate }\end{array}$ \\
\hline Plate cutting process: & Laser cutting \\
\hline Groove preparation: & I-shaped groove (no groove preparation) \\
\hline Weld consumable (Wire): & $\begin{array}{l}\text { Solid wire MG-50 (diameter, 1.6 mm) approved by } \\
\text { Nippon Kaiji Kyokai (Class NK) }\end{array}$ \\
\hline Shielded gas for arc welding: & Pure $\mathrm{CO}_{2}$ \\
\hline
\end{tabular}

Table 2. Specifications of the applied welding power sources.

\begin{tabular}{ll}
\hline Laser: & $\begin{array}{l}20 \mathrm{kw} \text { fiber laser } \\
\text { (IPG Photonics, YLS-20000-S2T) }\end{array}$ \\
\hline Shielded gas for arc welding: & $\begin{array}{l}\text { Digital inverter type } \mathrm{CO}_{2} \text { arc welding machines } \\
\text { (Daihen Welbee Inverter M500G) }\end{array}$ \\
\hline
\end{tabular}

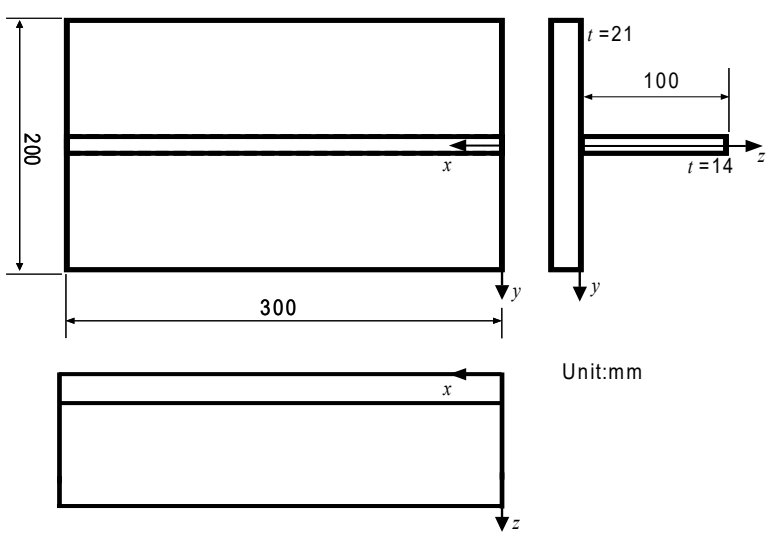

Fig. 1. Specimen configuration of the tee shaped joint for detecting the suitable welding condition.

In these investigative experiments, we set the laser head angle with horizontal $\theta_{L}$ at a low angle so that the boundary surface between the base plate and the stiffener connecting region lay within the laser irradiation area to increase the laser irradiation area to enlarge the melting region. 
Table 3. Control factors and noise factors for detecting the suitable welding condition.

\begin{tabular}{lc}
\hline Control factors & Level \\
\hline Laser power & 2 \\
\hline Arc current & 3 \\
\hline Arc voltage & 3 \\
\hline Defocusing distance, $D_{f}$ & 3 \\
\hline Arc torch angle, $\theta_{A}$ & 3 \\
\hline Laser head angle, $\theta_{L}$ & 3 \\
\hline Arc push angle, $\theta_{p}$ & 3 \\
\hline Laser drag angle, $\theta_{d}$ & 3 \\
\hline Noise factors & Level \\
\hline Wire extension, $d$ & 3 \\
\hline Laser radiation point, $H_{L}$ & 3 \\
\hline $\begin{array}{l}\text { Distance between web } \\
\text { surface and arc torch } \\
\text { aiming point, } D_{A W}\end{array}$ & 3 \\
\hline
\end{tabular}

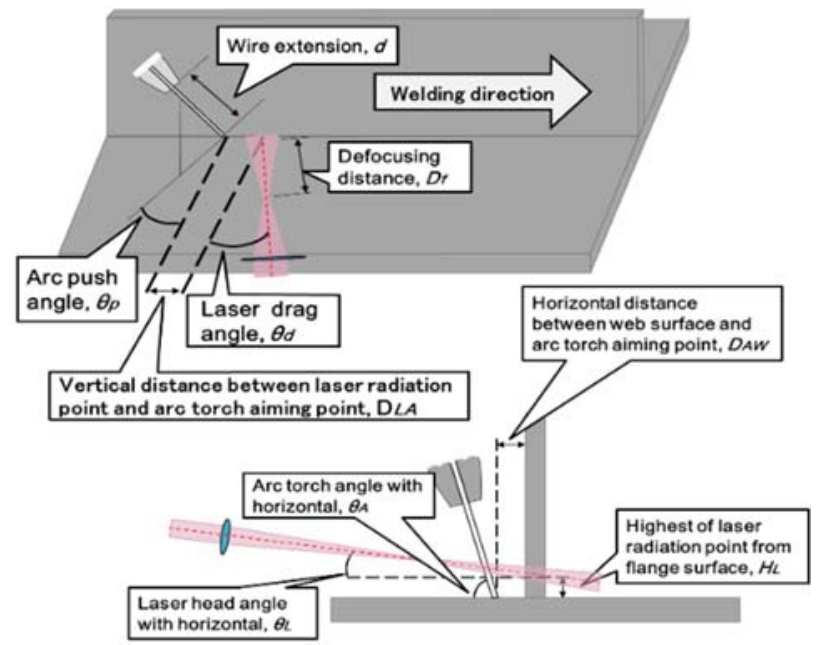

Table 4. Fixed welding conditions applied in this study.

\begin{tabular}{ll}
\hline Item & Value \\
\hline Joint gap $(\mathrm{mm}):$ & less than 0.05 \\
\hline Travel speed $(\mathrm{mm} / \mathrm{min}):$ & 900 \\
\hline $\begin{array}{l}\text { Distance between laser radiation point and arc torch aiming point, } D_{L A} \\
(\mathrm{~mm}):\end{array}$ & 3 \\
\hline
\end{tabular}

As a result of the above experiments, welding conditions were derived to obtain a joint with good bead appearance and no internal defects. Part of the welding condition is shown in Table 5 and the photograph of a cross section macroscopic observation is shown in Fig. 2. It is confirmed that a sound fitting can be manufactured up to a gap of $1.5 \mathrm{~mm}$ by finely adjusting the welding current and voltage.

Table 5. Detected suitable welding conditions.

\begin{tabular}{ll}
\hline Travel speed $(\mathrm{mm} / \mathrm{min}):$ & 900 \\
\hline Laser power $(\mathrm{kW}):$ & 20 \\
\hline Arc current $(\mathrm{A}):$ & 425 \\
\hline Arc voltage $(\mathrm{V}):$ & 27.3 \\
\hline Wire extension, $d(\mathrm{~mm}):$ & 3 \\
\hline $\begin{array}{l}\text { Vertical distance between laser radiation point and arc torch aiming } \\
\text { point, } D_{L A}(\mathrm{~mm}):\end{array}$ & 3 \\
\hline
\end{tabular}




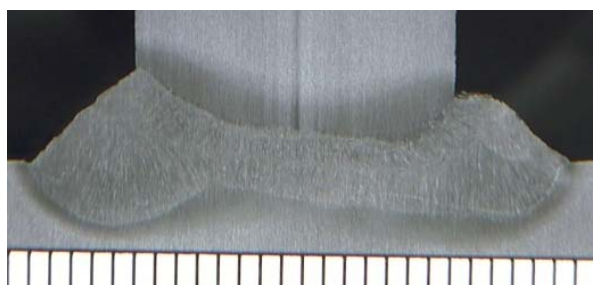

(a) $H_{L}=1.65 \mathrm{~mm}$

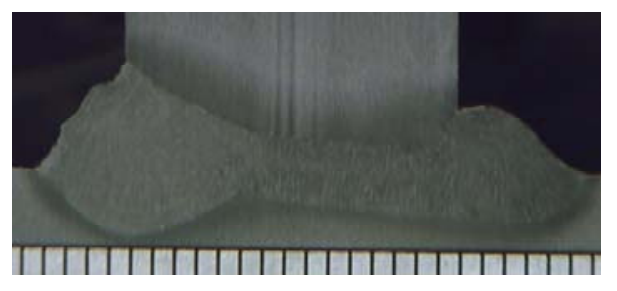

(b) $H_{L}=2.0 \mathrm{~mm}$

Fig. 2. Example of macroscopic observations.

\subsection{Mechanical test required guidelines}

The mechanical performance of the welded joint was investigated according to the Guidelines on Laser-Arc Hybrid Welding (ver.2) [4]. The test joint configuration to extract the specimens is shown in Fig. 3. In addition, the nondestructive tests (radiation inspection test, ultrasonic inspection test and magnetic particle inspection test) were performed to judge the integrity of the welded joint according to ISO 5817 [5] and acceptable results were obtained. Figure 4 shows the appearance of weld bead. Figure 5 shows the macroscopic observation of a cross section of the weld region. The Vickers hardness test was also performed and the measured maximum value was $258 \mathrm{HV}$, which was measured at the weld toe on the base plate of specimen M1. This value is less than the maximum allowable value of $380 \mathrm{HV}$.

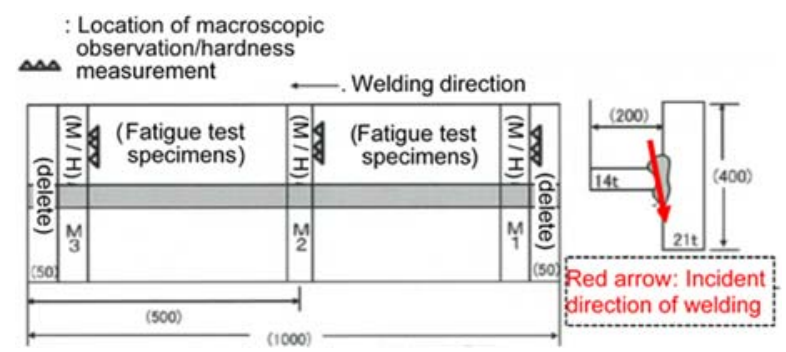

Fig. 3. Specimen configuration of the tee shaped joint (weld length, $1000 \mathrm{~mm}$ ).

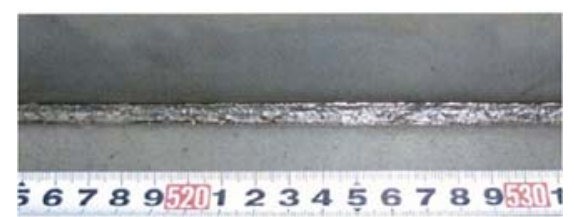

Front side

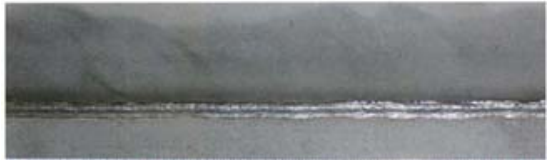

678952123456789530 Back side

Fig. 4. Appearance of a weld bead near the center of the welded joint. 


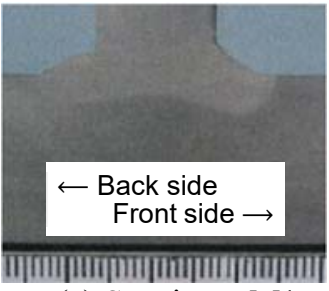

(a) Specimen M1

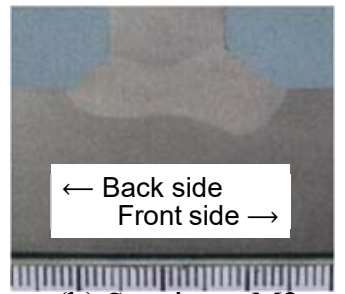

(b) Specimen M2

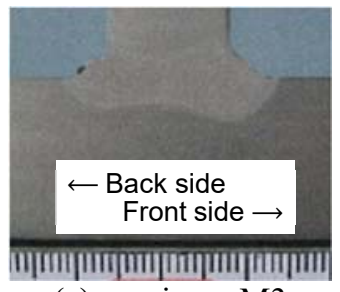

(c) specimen M3

Fig. 5. Macroscopic observations.

\subsection{Fatigue strength}

Although a fatigue test is required to approve the welding procedure, it is important to ensure the fatigue performance of welded joints in hull structures. Fatigue tests were performed to investigate the fatigue performance of the welded joints. Fatigue strength was investigated by conducting three-point bending with a zero stress ratio according to ISO TR14345-2002 [6]. A similar test was also conducted using a non-load carrying type cruciform shaped joint fabricated by the same welding procedure mentioned above.

Test results are shown in Fig. 6. Three fatigue design curves (IIW FAT100 for a transverse non-load-carrying tee joint with an as welded fillet [7], IIW FAT80 [7] and JSSC Class-E [8] for a transverse non-load-carrying tee joint with two-sided toe grounded fillets) are drawn in this figure. In addition, fatigue test results for the twinpass tee welded joint fabricated by the hybrid welding presented in PRADS 2016 [3] are plotted.

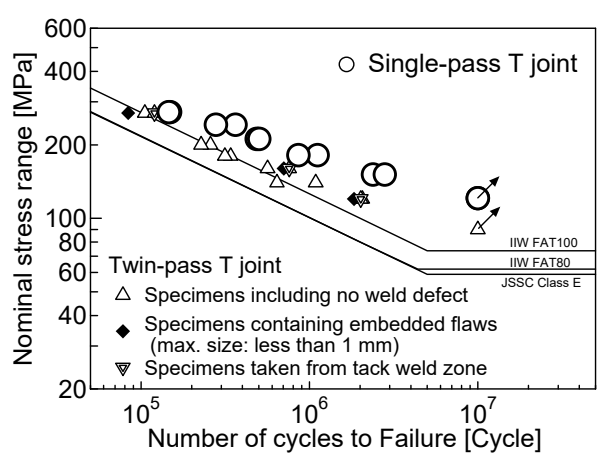

(a) Tee joint

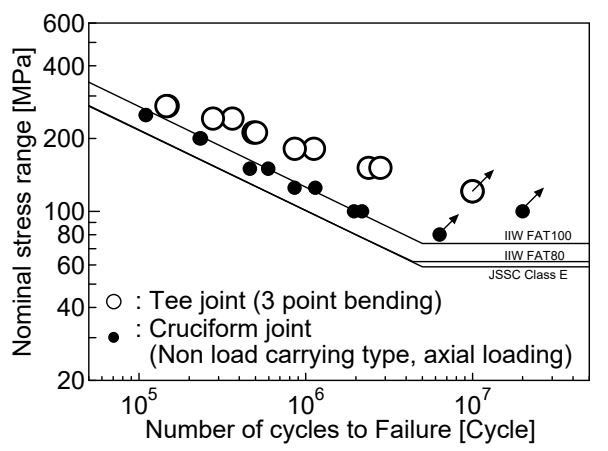

(b) Non-load carrying type cruciform joint

Fig. 6. S-N curves.

All joints fabricated by one side single pass welding had high fatigue performance compared with the IIW FAT 80 fatigue design curve and twin-pass welded joints. Remarkably, the slope of the S-N curve of the tee joint fabricated by single pass welding is shallow compared with the others. However, the slope of the S-N curve of the cruciform joint is similar to the design curves. The reason is that the joint might contain 
misalignment. By considering such high-fatigue performance, it is expected that most fillet welded joints in a hull structure can be replaced with laser-arc hybrid welded joints.

\section{Influence of the weld groove processing method}

\subsection{Influence of groove shape cutting methods on joint quality}

Because the accuracy of groove preparation generally affects the joint quality of hybrid welds, European shipyards, which are leaders in the introduction of hybrid welding for passenger ships, apply mechanical cutting to groove preparation. In general merchant ship construction, groove preparation by thermal cutting is suitable in terms of cost. For this reason, previous studies [3] have been restricted to laser cutting that has excellent cutting accuracy in thermal cutting for the groove preparation method. However, plasma and gas cutting are often used in Japanese shipyards, and there are grooves (e.g. Y-shaped grooves) that can be processed only by only gas cutting. Therefore, in the case of groove processing by plasma or gas cutting, welding conditions for manufacturing a good quality joint by hybrid welding were examined. The applied materials are the same as in Table 1.

Suitable welding conditions were detected by conducting a similar procedure described in the previous section. However, only visual inspection of bead appearance, cross section macroscopic observation and Vickers hardness measurement (measured maximum value, $297 \mathrm{HV}$, which is less than the allowable limit of $380 \mathrm{HV}$ ) was conducted to judge the validity. The obtained results are shown in Table 6 . This condition is applicable to the maximum gap of $0.5 \mathrm{~mm}$. Thermal cutting conditions for plasma and gas cutting are followed as the standard cutting conditions in shipyards. The arithmetically average groove surface roughness of a specimen fabricated by plasma and gas cutting were about $3 \mu \mathrm{m}$ and $10.5 \mu \mathrm{m}$. The value by plasma cutting is almost the same as laser cutting.

Table 6. Detected suitable welding conditions.

\begin{tabular}{ll}
\hline Travel speed $(\mathrm{mm} / \mathrm{min}):$ & 1200 \\
\hline Laser power $(\mathrm{kW}):$ & 12 \\
\hline Arc current $(\mathrm{A}):$ & 400 \\
\hline Arc voltage $(\mathrm{V}):$ & 26.0 \\
\hline
\end{tabular}

Figure 7 shows the bead appearance and macroscopic observation of the joints for which groove preparation was conducted by plasma and gas cutting. In both cases, spatter was observed on the front bead-side surface, but the bead shape itself was good. In addition, no weld defects were observed on the cross section of the weld bead. By considering these results, it is expected that plasma and gas cutting can be applied to groove preparation for laser-arc hybrid welding. 


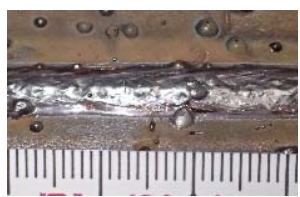

(1) Front side appearance
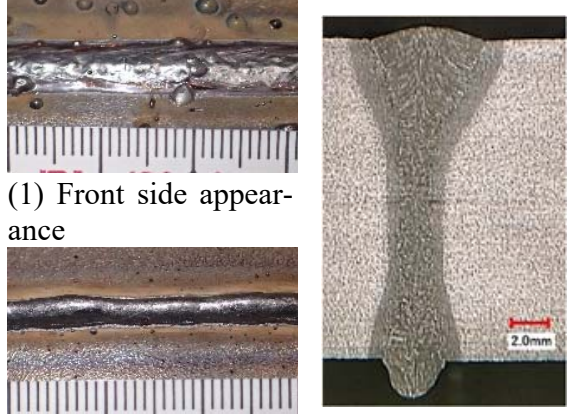

(2) Back-side appear- (3) Cross section macance roscopic observation

(a) Groove preparation by plasma cutting

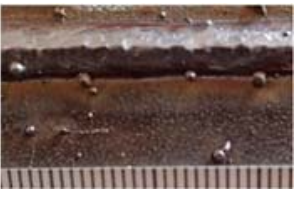

(1) Front side appearance

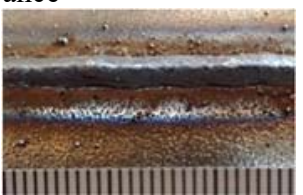

(2) Back-side appear- (3) Cross section macance roscopic observation

(b) Groove preparation by gas cutting.

Fig. 7. Comparison of bead appearances and cross sections by different groove preparation methods.

\subsection{Influence of retained primer and oxide film on joint quality}

In general, it is useful to remove the antirust primer near connected regions prior to construction to prevent the formation of weld defects. In the case of groove preparation by thermal cutting, welding defects sometimes occur if an oxide film remains on the groove surface, as in the case of the primer. However, the conventional arc welding used in the standard shipbuilding process enables fabrication of a good quality welded joint without removing the primer and the oxide film in advance. Therefore, it is necessary to enable fabrication of good quality joints, even if the primer and oxide film remain. The influence on joint quality when these are retained near the connection region was investigated. The test condition of the primer and oxide film is shown in Table 7. The primer and oxide film were removed by a disk grinder. Bead appearances and macroscopic observations of each specimen are shown in Fig. 8.

Table 7. Test conditions.

\begin{tabular}{ccccc}
\hline $\begin{array}{c}\text { Specimen } \\
\text { ID }\end{array}$ & $\begin{array}{c}\text { Joint } \\
\text { type }\end{array}$ & $\begin{array}{c}\text { Gap } \\
(\mathrm{mm})\end{array}$ & Primer & $\begin{array}{c}\text { Oxide film on the groove sur- } \\
\text { face }\end{array}$ \\
\hline B1 & Butt & 0.5 & Retained on the front surface only & Removed \\
\hline B2 & Butt & 0.5 & Retained on the back surface only & Removed \\
\hline B3 & Butt & 0.5 & Removed & Retained \\
\hline T1 & Tee & 0 & Removed & Removed \\
\hline T2 & Tee & 0 & Retained & Retained \\
\hline
\end{tabular}




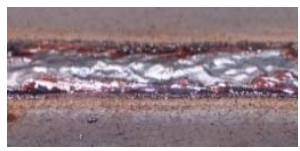

(1) Front-side appearance
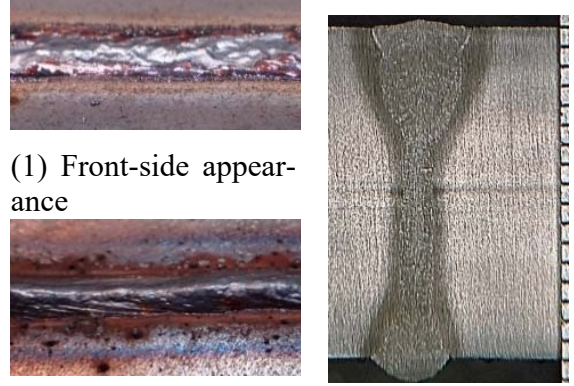

(2) Back-side appear- (3) Cross section macance roscopic observation

(a) Specimen B1
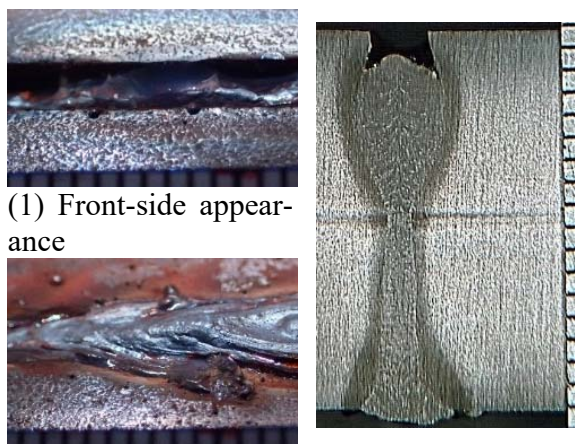

(2) Back-side appear- (3) Cross section macance

roscopic observation

(c) Specimen B3

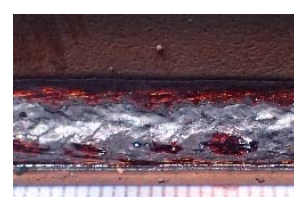

(1) Front-side appearance
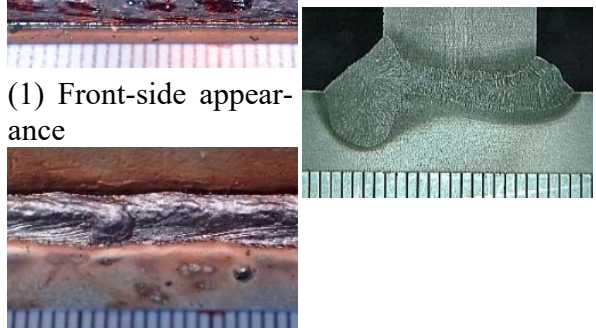

(2) Back-side appear- (3) Cross section macance roscopic observation

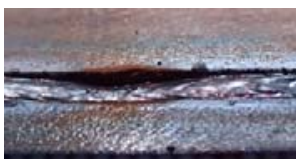

(1) Front-side appearance
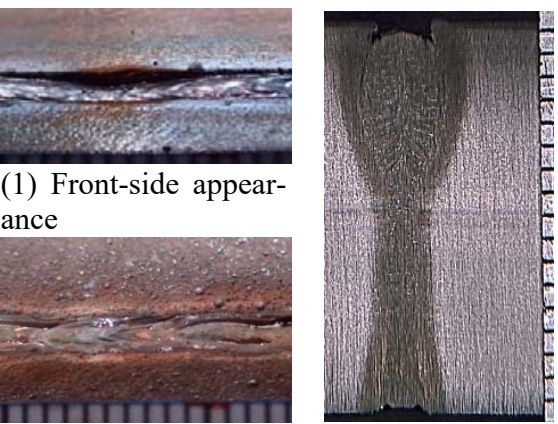

(2) Back-side appear- (3) Cross section macance

(b) Specimen B2 roscopic observation

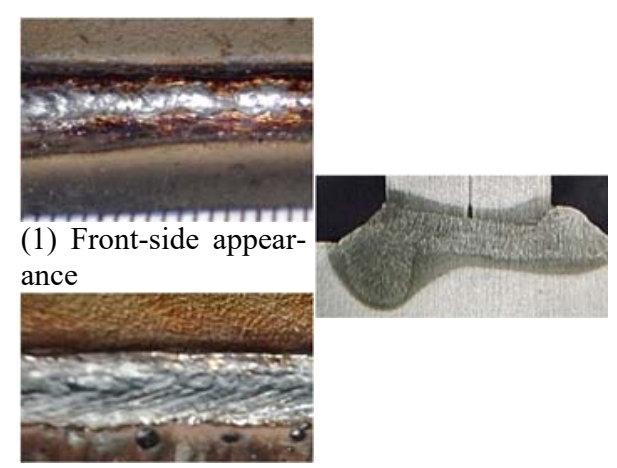

(2) Back-side appear- (3) Cross section macance roscopic observation

(d) Specimen T1

(e) Specimen T2

Fig. 8. Weld bead appearance and macroscopic observation. 
In specimen B1, although a slight decrease in surface bead height was confirmed, a good bead appearance and cross section were obtained. However, underfill occurs on both the front and back beads in specimen B2 and occurs on the front-side bead in specimen B3. These results indicate that the primer on the back surface of the test specimen and the oxide film can contribute to the formation of defects when producing a welded joint using hybrid welding. As a cause of the generation of the underfill, it is considered that the primer and the oxide film are thermally decomposed by welding to generate carbon monoxide (CO) gas, and the gas stirs the molten pool and scatters from the back surface of the material. The gas generated when the oxide film is thermally decomposed by laser welding and the gas generated when the primer is thermally decomposed by arc welding contains a large amount of $\mathrm{CO}$. In the case of the primer on the front surface, it is presumed that the primer effect does not occur because the gas generated at the time of welding is released into the atmosphere and is not mixed in the molten pool. However, a good bead appearance and no defects were observed in the case of the tee joint, see Fig. 8 (d) and (e). The generated CO gas is released and not mixed in the molten pool because the preceding laser beam drills a tunnel and the gas can be released into the atmosphere.

\section{$4 \quad$ Application of weld seam tracking technology}

To construct long welded joints with allowable quality, it is necessary to track the weld line and gap variation, and to appropriately change the welding conditions when necessary. This JIP focused on the seam tracking device for welding in automobile manufacturing, as reported by some authors [9][10][11], and examined the possibility of stable long-distance welding by introducing this device. The approximate installation location of the sensor is shown in Fig. 9.

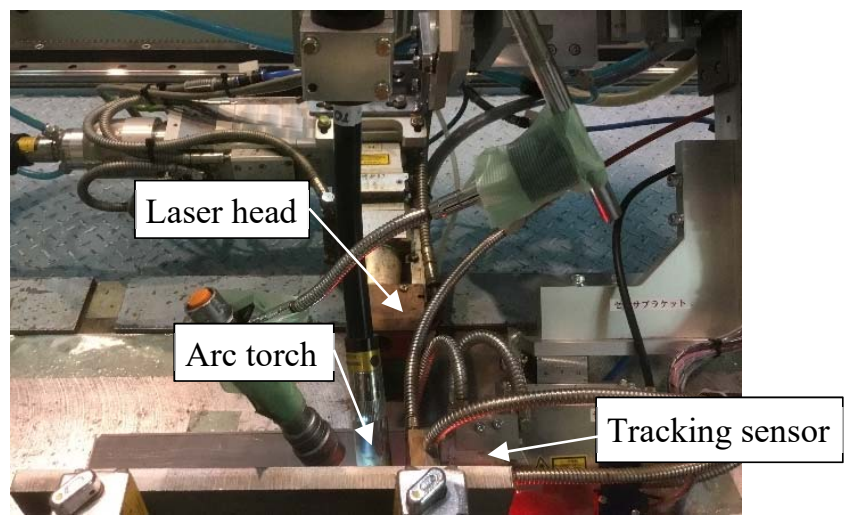

Fig. 9. Tracking sensor. 
Top View

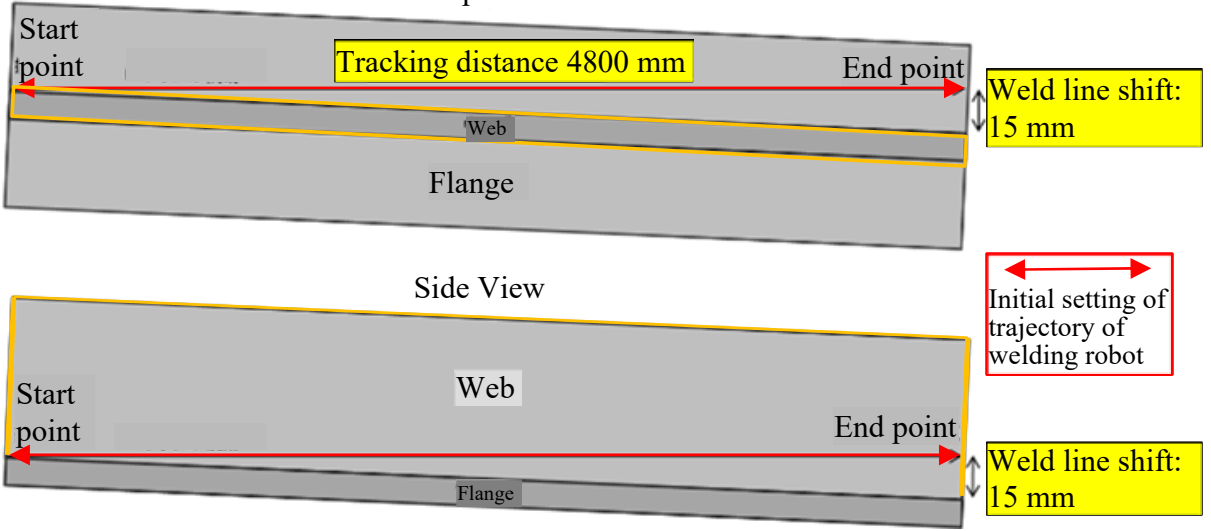

Fig. 10. Specimen setting condition.

As shown in Fig. 10, the welding line was aimed at the start point, and the specimen was set up by lifting the flange so that the welding target positions were each shifted $15 \mathrm{~mm}$ away from the end point. To perform welding with the seam tracking function enabled, the specimen was deformed freely during welding by clamping the two ends of the specimen only. From the information obtained by tracking, linear interpolation teaching of only the start and end points was performed. In the evaluation, the imaging window was checked visually to determine whether the sensor was contaminated with fumes or spatters during the welding. The welding line was also checked to determine whether missed or abnormal values could be removed. Verification was performed at a welding length of $4800 \mathrm{~mm}$, a laser power of $20 \mathrm{~kW}$, a welding current of $300 \mathrm{~A}$, and a speed of $1000 \mathrm{~mm} / \mathrm{min}$.

It was confirmed that, in the case of dry operation (with only a robot moving without laser and arc welding), sufficient tracking accuracy was obtained. However, at the time of construction of a full-penetration tee joint by one-side single-pass welding, the lens of the weld line detection sensor became cloudy because of fumes, so detection accuracy decreased as the welding length became longer, and the sensor overheated, confirming that the durability was insufficient. Therefore, we have taken measures such as installing an air purge mechanism for fume removal and a cooling mechanism near the sensor. As a result, it was confirmed that tracking was possible within $\pm 0.2 \mathrm{~mm}$ for both aiming and height deviation.

In the hybrid welding condition, examination of a full-penetration tee joint by oneside single-pass welding with a welding length of $2000 \mathrm{~mm}$, even in a situation where the target position changes significantly because the tacking was removed after the welding length of $1000 \mathrm{~mm}$, confirms that the tracking mechanism remains operational. Figure 11 shows the appearance of the specimen and the amount of horizontal displacement of the upright plate corresponding to this examination. 


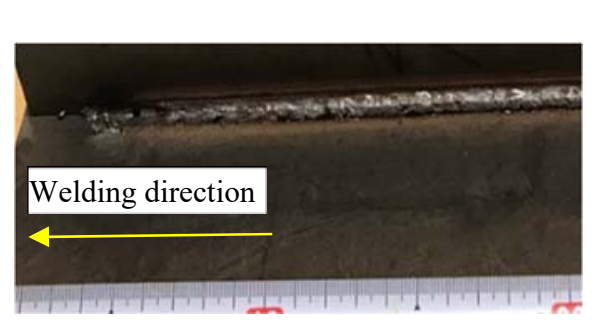

(a) Front bead appearance; from $1800 \mathrm{~mm}$ to $2000 \mathrm{~mm}$

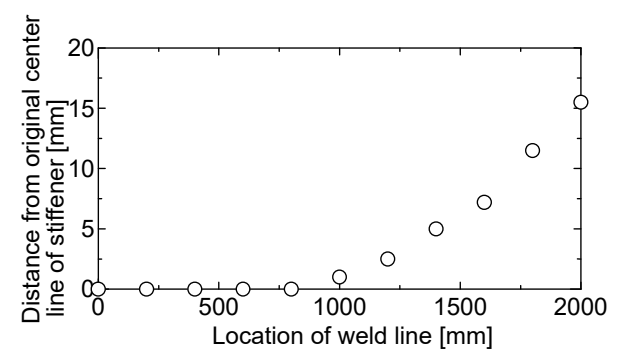

(b) Horizontal deflection of the stiffener along the weld length.

Fig. 11. Performance check result of the tracking system.

\section{Prototyping of a 5-m-long welded joint}

Using the above-mentioned seam tracking system, a full-penetration tee joint was manufactured by one-side single-pass welding with a total length of $5000 \mathrm{~mm}$. As a limitation of the laser oscillator performance, the laser power decreases as the continuous construction time increases. Therefore, the construction was temporarily stopped at a welding length of $2000 \mathrm{~mm}$, and then $3000 \mathrm{~mm}$ was constructed. In addition, the laser power was automatically changed according to the gap width obtained by seam tracking while finely adjusting the part of the welding conditions derived by this JIP. The initial gap was set to $1.5 \mathrm{~mm}$ from the viewpoint of the tracking detection.

Examples of the bead appearance for the range of the first welding length of 2000 $\mathrm{mm}$ are shown in Fig. 12. The front bead was separated from the web plate in some sections and a bead formed on the base plate. The back bead was poured into the backside of the web through the through hole created by the leading laser irradiation, and it is estimated that the target position of the subsequent arc is improperly shifted because of this effect. Figure 13 (a) shows the change of the laser power during welding. It was confirmed that gap width detection by tracking and laser power control according to the laser power changes were appropriate. A 1.5 -mm-thick filler gauge was inserted between the web and base plates at intervals of $500 \mathrm{~mm}$ for setting the initial gap, so it was judged that the gap was $0.0 \mathrm{~mm}$ and the laser power increased instantaneously.

Examples of the appearance of a bead with a welding length of $3000 \mathrm{~mm}$ are shown in Fig. 14, and the laser power history during welding is shown in Fig. 13 (b). It is confirmed from Fig. 14 that the back bead becomes wavy from around $3700 \mathrm{~mm}$. The laser power history at this point (about 113 seconds in Fig. 13 (b)) was about $17 \mathrm{~kW}$. However, stable back beads were formed with the same level of output at a welding length of $2750 \mathrm{~mm}$ (about 50 seconds in Fig. 13 (b)). The reason the back bead shape is different even when the laser power is the same might be that the power decrease from the laser focal shift due to the thermal expansion of lens occurred. Another possibility is that fume and plume stagnation around the processing point occurred. However, the reason for this phenomenon has not yet been identified. The front bead was very short in leg length and formed a bead along the web plate. Considering the size of the back bead, it is believed that the total amount of filler metal is insufficient at the 
current welding wire feed amount, and it is necessary to make adjustments such as reducing the welding speed. The laser power fluctuates in six sections divided by filler gauge insertion, which is consistent with the number of sections between filler gauges installed at a welding length of $3000 \mathrm{~mm}$ (installation interval, $500 \mathrm{~mm}$ ). It can be confirmed that each function of the tracking device was fully exhibited.

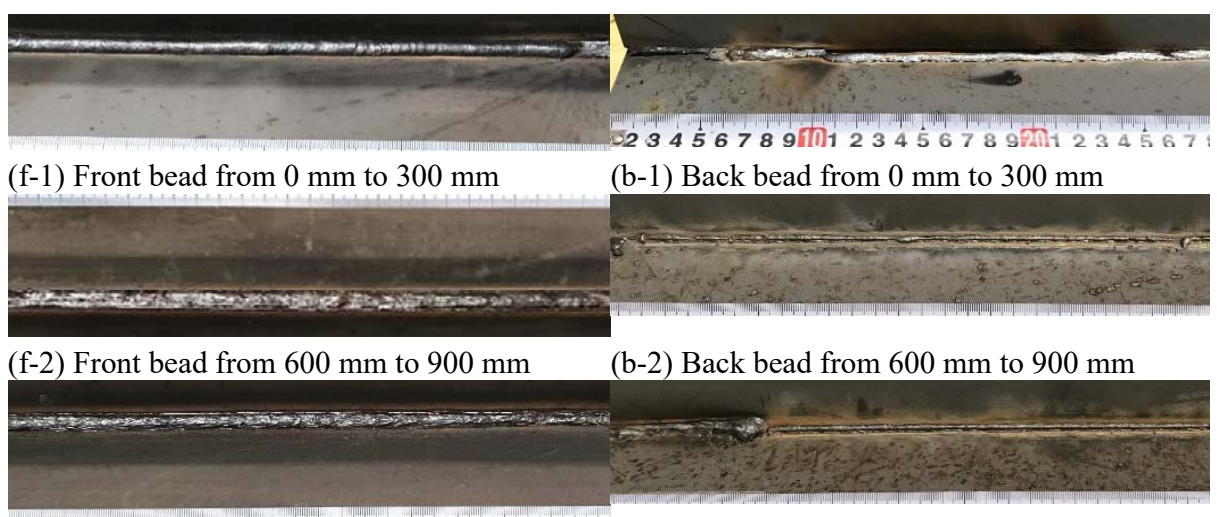

(f-3) Front bead from $1500 \mathrm{~mm}$ to $1800 \mathrm{~mm}$

(b-3) Back bead from $1500 \mathrm{~mm}$ to $1800 \mathrm{~mm}$

Fig. 12. Weld bead appearance on a full-penetration tee joint fabricated by one-side single pass welding. (Welding section from $0 \mathrm{~mm}$ to $2000 \mathrm{~mm}$ ).

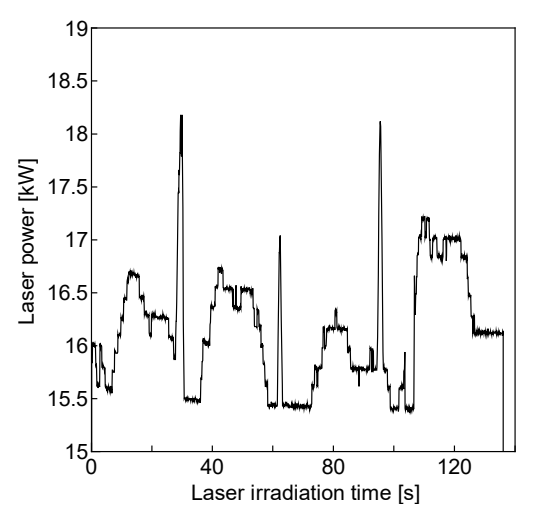

(a) Welding section: $0 \mathrm{~mm}$ to $2000 \mathrm{~mm}$

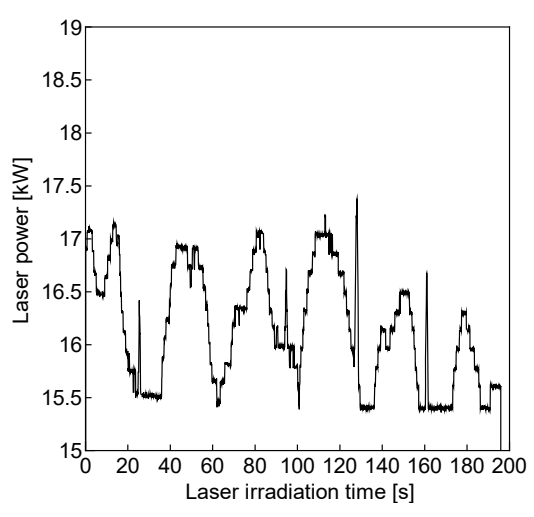

(b) Welding section: $2000 \mathrm{~mm}$ to $5000 \mathrm{~mm}$

Fig. 13. History of laser power during the welding.

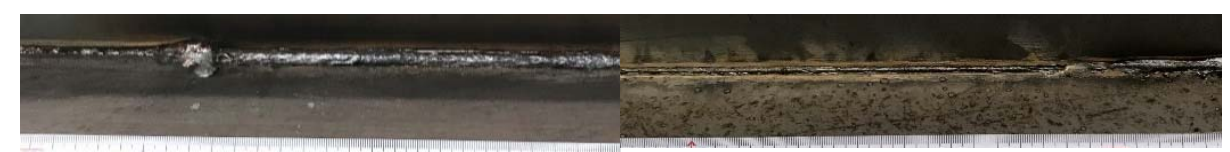

(f-1) Front bead from $2000 \mathrm{~mm}$ to $2100 \mathrm{~mm} \quad$ (b-1) Back bead from $2000 \mathrm{~mm}$ to $2100 \mathrm{~mm}$ 

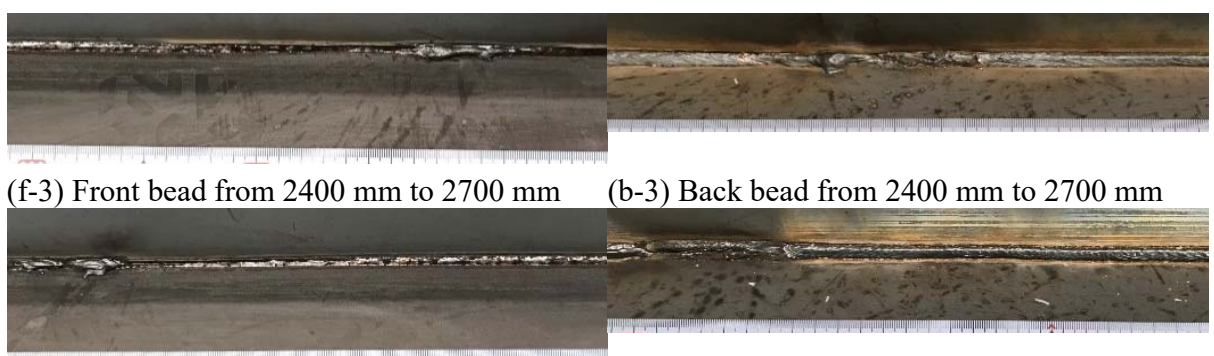

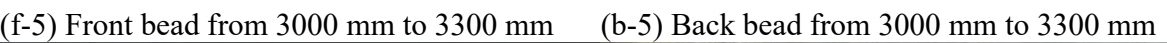

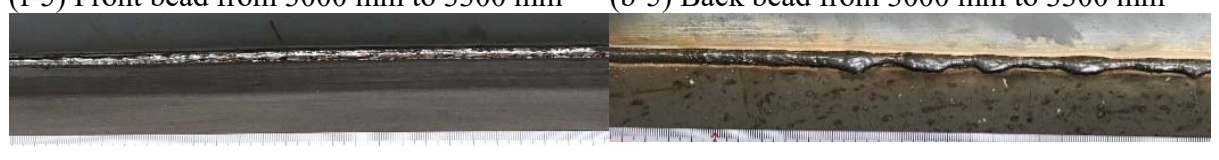

(f-7) Front bead from $3600 \mathrm{~mm}$ to $3900 \mathrm{~mm} \quad$ (b-7) Back bead from $3600 \mathrm{~mm}$ to $3900 \mathrm{~mm}$

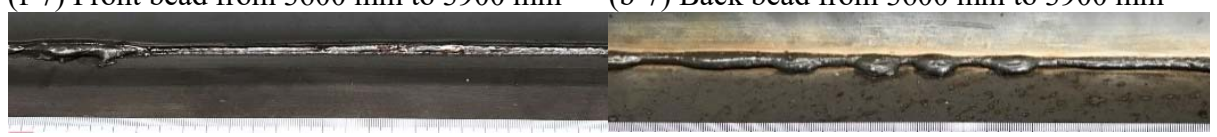

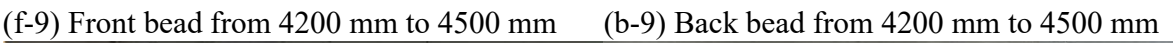

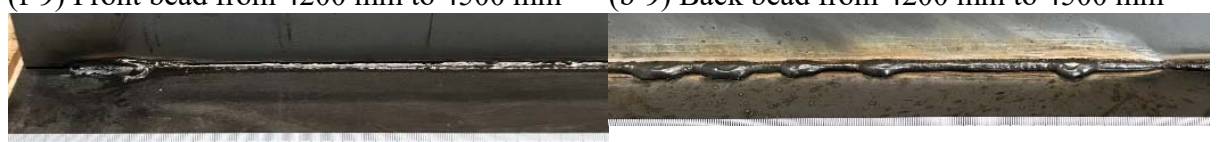

(f-11) Front bead from $4800 \mathrm{~mm}$ to $5000 \mathrm{~mm}$ (b-11) Back bead from $4800 \mathrm{~mm}$ to $5000 \mathrm{~mm}$

Fig. 14. Weld bead appearance on a full-penetration tee joint fabricated by one-side single pass welding. (Welding section from $2000 \mathrm{~mm}$ to $5000 \mathrm{~mm}$ ).

\section{Concluding remarks and future challenges}

The second phase research project for introducing laser-arc hybrid welding in the construction of general merchant ships has been conducted and the following results were obtained.

1. Welding conditions to fabricate a good quality full-penetration tee joint by one-side single-pass welding were examined.

2. The influence of groove shape cutting methods was investigated and the possibility of application of other thermal cutting methods (plasma and gas cutting) was confirmed.

3. The influence of retained primer near weld line and oxide film on the groove surface on the joint quality was investigated, and the necessity of removal of both contaminants during butt welding was confirmed.

4. It was confirmed that stable weld seam line tracking was possible during long-distance welding by using a seam tracking system.

Further Challenges related to this research are as follows.

1. Expansion of welding conditions, e.g. applicable plate thickness and gap width. 
2. Application to other welding positions (horizontal, vertical and overhead positions).

3. Examination of fatigue performance of load carrying type cruciform joints.

4. Examination of fracture toughness in each notch position.

\section{Acknowledgement}

This research was conducted as a joint research project with the Shipbuilding Research Center of Japan and other shipyards, with the organizing committee set up at the Japan Ship Technology Research Association (JSTRA). The authors express their appreciation to the National Maritime Research Institute for the fatigue test of cruciform joints and to the JFE Steel Corporation for providing steel plates.

\section{References}

1. Gerriten, C., Howarth, D.: A Review of the development and application of laser and laserArc hybrid welding in European shipbuilding. In Proceedings of 11th CF/DRDC International Meeting on Naval Applications of Materials Technology, Halifax, NS, Canada, 7-9, (2005).

2. Koga, H., Goda, H., Terada, S., Hirota, K., Nakayama, S., Tsubota, S.: First Application of Hybrid Laser-arc Welding to Commercial Ships, Mitsubishi Heavy Industries Technical Review, 47(3), 59-64, (2010).

3. Gotoh, K., Fukui, T., Moriyama, A., Tsumura, S. and Sawato, H.: Overview of a joint industrial project for introducing laser-arc hybrid welding to the construction of general merchant ships in Japan, In Proceedings of 14th Practical Design of Ships and Other Floating Structures (PRADS 2016), ID 014, (2016).

4. Nippon Kaiji Kyokai (ClassNK): Guidelines on Laser-Arc Hybrid Welding (Ver.2), (2015).

5. ISO 5817-2014: Welding -Fusion-welded joints in steel, nickel, titanium and their alloys (beam welding excluded) - Quality levels for imperfections, (2014).

6. ISO TR14345-2002: Fatigue -Fatigue testing of welded component- Guidance, (2002).

7. Hobbacher, A.: Fatigue Design of Welded Joints and Components -Recommendations of IIW Joint Working Group XIII-XV-, Woodhead, (1996).

8. Mori, T, Minami, K., Kabuto, Y.: Review of Fatigue Strength of Welded Joints Specified in the JSSC Fatigue Design Recommendations, Kou Kouzou Rombunshuu, 18(69), pp.71-81, (2011), https://doi.org/10.11273/jssc.18.69_71.

9. Maeda, T., Torigoe, I, Kutsuna, M.: Study on Seam Tracking for Laser Welding, In Proceedings of Japan Welding Society Annual Meeting, 99, pp. 64-65, (2016), (In Japanese).

10. Maeda, T., Torigoe, I, Kutsuna, M.: Study on Seam Tracking and Adaptive Control for Laser-Arc Hybrid Welding, In Proceedings of Japan Welding Society Annual Meeting, 100, pp. 58-59, (2017), (In Japanese).

11. Maeda, T., Torigoe, I, Kasuga, S., Kutsuna, M.: Study on Seam Tracking System for Laser Welding using Tack Welds Identification Function, In Proceedings of Japan Welding Society Annual Meeting, 101, pp. 358-359, (2017), (In Japanese). 